\title{
A More Realistic Study on the Mechanical Properties of CFRC Composite Grouting Material under a Long-Term Water Immersion Process
}

\author{
Yao Xiao, ${ }^{1}$ Huafeng Deng $\mathbb{D}^{1},{ }^{1}$ Jianlin $\mathrm{Li}^{1},{ }^{1}$ and Eleyas Assefa ${ }^{2}{ }^{2}$ \\ ${ }^{1}$ Key Laboratory of Geological Hazards on Three Gorges Reservoir Area (China Three Gorges University), Ministry of Education, \\ Yichang, Hubei 443002, China \\ ${ }^{2}$ College of Architecture and Civil Engineering, Addis Ababa Science and Technology University, Addis Ababa, Ethiopia
}

Correspondence should be addressed to Huafeng Deng; dhf8010@ctgu.edu.cn

Received 17 June 2019; Revised 21 August 2019; Accepted 6 September 2019; Published 3 October 2019

Academic Editor: Meng Zhang

Copyright (c) 2019 Yao Xiao et al. This is an open access article distributed under the Creative Commons Attribution License, which permits unrestricted use, distribution, and reproduction in any medium, provided the original work is properly cited.

The long-term effect of water immersion on the mechanical properties of CFRC composite grouting materials was studied by using five different carbon fiber contents $(0,0.25 \%, 0.50 \%, 0.75 \%$, and $1.00 \%)$. The direct shear and long-term immersion tests were performed based on the specified and optimum values of carbon fiber content, respectively. The results showed the following: (1) the application of carbon fiber significantly improved the shear resistance of CRFC composite grouting material by using "reinforcing" and "anchoring" actions. The shear strength of the specimen was increasing by 5.66\% 43.41\% when the carbon fiber content increased from $0.25 \%$ to $1.00 \%$. After a comprehensive analysis, the optimum carbon fiber content was found to be $0.75 \%$. (2) The degradation in the compressive and tensile strength of CRFC composite specimens exhibited a consistent trend (i.e., a steep gradient was gradually followed by a gentle slope) under a long-term water immersion process. About $90 \%$ of the total degradation in the compressive and tensile strength has occurred in 90 immersion days (i.e., $16.05 \%$ and $18.45 \%$, respectively). In comparison, the degradation in the tensile strength (20.05\%) was slightly higher than the compressive strength (18.16\%). (3) Under the long-term water immersion process: the properties of the specimens were gradually deteriorating, the carbon fibers were gradually reaching a fatigue stage, and the bonding properties of carbon fiber was decreasing, which resulted in a reduction in the compressive and tensile strength. The uniaxial compression failure mode changed from brittle to ductile, and the development of local failure was very noticeable. Based on the findings of this paper, groundwater has a significant impact on the mechanical properties of grouted rock mass such as dam foundations and abutments. Therefore, the degradation in the grouting materials has to be considered in practical cases.

\section{Introduction}

Carbon fiber-reinforced cement (CFRC) composite material refers to a new composite material with cement as the substrate and carbon fiber as the reinforcement. Because carbon fiber has the advantages such as being lightweight and having high strength, large modulus, and strong corrosion resistance $[1,2]$, it can effectively prevent the production of microcracks caused by bleeding, shrinkage, and temperature change during the consolidation process of cement-based slurry. At the same time, it can prevent or delay the occurrence and expansion of deformation and failure of cement-based solids during the loading process, improve the mechanical properties such as flexural, tensile, antifreezing, and antiseepage, and also achieve the strengthening and toughening effect of fiber materials [3-6]. It has very few negative impacts on the environment. Therefore, CFRC composite materials have a wide range of applications in the field of civil engineering.

On the one hand, some scholars conducted many experimental studies on the effect of carbon fiber content on the performance of CFRC composites. Xiong et al. [7], Hai et al. [8], and Yu et al. [9] performed uniaxial compression and tensile tests on composites with different carbon fiber 
contents. Based on their findings, the mechanical properties such as fracture toughness, Poisson's ratio, and compressive strength were increasing when the carbon fiber content increased within a certain content range. However, the apparent density and elastic modulus showed a decreasing trend. Sun and Wei [10], and Wang and Zhang [11] revealed the performance of carbon fiber in the composite material to improve the resistivity or pressure-sensitive property within a certain amount. Nonetheless, its effect on the electrical properties was not clear with low or high carbon fiber content. The results of those studies show that different carbon fiber contents can enhance the physical, mechanical, and electrical properties of CFRC composites to varying degrees. However, the performance of stabilizer is not clear when the carbon fiber content is too high or too low, and the optimum amount of carbon fiber is not unique for different material compositions or ratios. Moreover, few studies were available on the shear resistance of CFRC composites.

On the other hand, when CFRC composites are used for practical purposes, they are inevitably affected by temperature, humidity, erosion, freezing, and thawing etc., resulting in a series of physical and chemical reactions, which in turn lead to the deterioration of composite properties. Therefore, one should study the durability of CFRC composites under different environmental conditions. For example, Shrestha et al. [12] and Zhang [13] evaluated the shear bond strength of CFRC composites under long-term wet condition or seawater corrosion attack. They found that the strength was gradually decreasing while the experimental duration increased. Gong et al. [14], Ren et al. [15], and other studies have shown that the compressive and tensile strength of CFRC ribs has a certain degree of decreasing trend under seawater cyclic dry-wet condition or cyclic freeze-thaw condition. These results have laid a good foundation for the study of durability properties of CFRC composite grouting materials.

As a high-performance grouting material, CRFC composite material is commonly used to improve the dam foundation and fractured abutments in many hydropower projects. After the commencement of the hydropower project, the reservoir water level will increase significantly. After the grouting treatment, the grouted rock mass will be affected by high water pressure under long-term soaking condition. However, previous studies do not consider this environmental phenomenon for CFRC composite grouting materials. To capture this scenario: firstly, the shear resistance of CRFC composites at different carbon fiber contents was studied, and the optimum carbon fiber content was determined. The uniaxial compression and splitting tensile tests were conducted to investigate the rate and degradation mechanism of the CRFC composite grouting materials under different water immersion durations.

\section{Materials and Methods}

2.1. Materials. In this study, the CFRC composite material was prepared based on the recommended ratio of cementitious material, admixture, water, and carbon fiber [16-21]. The cementitious material is composed of ultrafine cement, fly ash, mineral powder, silica fume, quartz sand powder, sodium sulfate, slaked lime, magnesium oxide, and sodium silicate. The compositions are tabulated in Table 1. Admixtures mainly consist of water-reducing agents and retarders.

In this experiment, PAN-based chopped carbon fiber (manufactured by Sinosteel Shanghai Carbon Factory Co., Ltd.) together with polyacrylonitrile was used as a raw material. The basic properties are shown in Table 2 .

The effect of carbon fiber on the mechanical properties of CFRC composites was studied based on the existing literature [17-22]. The samples were prepared by using five different carbon fiber contents ( 0 or no carbon fiber, $0.25 \%$, $0.50 \%, 0.75 \%$, and $1.00 \%$ ).

Sample preparation procedures for CFRC composites are described as follows. Firstly, the composite materials were prepared and thoroughly mixed in a cement net pulp mixer based on their percentage by mass (Table 1). Secondly, based on the experimental design, five kinds of carbon fiber contents were taken and uniformly mixed with water. Thirdly, the slurry (from step 2) was poured into cementitious material (prepared in step 1). A uniformly mixed slurry was placed in a mold $(50 \mathrm{~mm}$ diameter by $100 \mathrm{~mm}$ height) and kept in a curing box at a constant temperature and humidity. The mechanical tests were conducted after 28 days of curing time. The specimens are shown in Figure 1.

2.2. Experimental Methods. A grouted rock mass will be subjected to compression, tension, and shear stresses. The shear resistance of the grouting material is an important evaluation index. For this reason, firstly, the specimens of different carbon fiber contents were subjected to shear tests under the specified normal stresses $(0.5 \mathrm{MPa}, 1.0 \mathrm{MPa}$, 1.5 $\mathrm{MPa}, 2.0 \mathrm{MPa}$, and $2.5 \mathrm{MPa}$ ), and the optimum carbon fiber content was determined. Then, the specimens were prepared based on the optimum carbon fiber content, and they were subjected to uniaxial compression and splitting tensile tests with different immersion durations to investigate the degradation mechanism of the CFRC composites. The testing program is shown in Figure 2.

The shear tests were conducted by using computerized direct shear apparatus known as YZW1000 (Figure 3(a)). The shear loading device is shown in Figure $3(\mathrm{~b})$. The specimens were mounted on the testing device with a seating load and tested under different normal loads $(0.5,1.0,1.5$, 2.0, and 2.5 MPa). Then, the shear load was applied at a controlled rate of deformation until residual strength was established. The uniaxial compression and splitting tensile tests have been conducted by using the RMT-150C rock mechanics test system (Figure 4(a)). The loading devices used for the uniaxial compression and split tensile strength tests are shown in Figures 4(b) and 4(c), respectively. In this study, a load-controlled method was adopted. The uniaxial compression and splitting tensile tests were performed at a rate of $0.5 \mathrm{kN} / \mathrm{s}$ and $0.1 \mathrm{kN} / \mathrm{s}$, respectively. In the meantime, the test was automatically stopped at failure.

In the immersion test, the design soaking water pressure is $0.5 \mathrm{MPa}$, and the total immersion time is 150 days. Among 
TABLE 1: Composition of composite substrate cementing material.

\begin{tabular}{|c|c|c|c|c|c|c|c|c|c|}
\hline $\begin{array}{l}\text { Cementitious } \\
\text { material }\end{array}$ & $\begin{array}{l}\text { Ultrafine } \\
\text { cement }\end{array}$ & $\begin{array}{l}\text { Fly } \\
\text { ash }\end{array}$ & $\begin{array}{l}\text { Mineral } \\
\text { powder }\end{array}$ & $\begin{array}{l}\text { Silica } \\
\text { fume }\end{array}$ & $\begin{array}{c}\text { Quartz sand } \\
\text { powder }\end{array}$ & $\begin{array}{l}\text { Sodium } \\
\text { sulfate }\end{array}$ & $\begin{array}{c}\text { Slaked } \\
\text { lime }\end{array}$ & $\begin{array}{l}\text { Magnesium } \\
\text { oxide }\end{array}$ & $\begin{array}{l}\text { Sodium } \\
\text { silicate }\end{array}$ \\
\hline $\begin{array}{l}\text { Mass } \\
\text { ratio (\%) }\end{array}$ & 53.76 & 10.75 & 10.75 & 3.76 & 5.38 & 1.08 & 5.38 & 3.76 & 5.38 \\
\hline
\end{tabular}

TABLE 2: Physical properties of carbon fiber.

\begin{tabular}{lccccc}
\hline Type & Average length & Fiber diameter & Tensile strength & Tensile modulus & Density \\
\hline PAN & $5 \mathrm{~mm}$ & $7 \mu \mathrm{m}$ & $2 \sim 3 \mathrm{GPa}$ & $175-215 \mathrm{GPa}$ & $1.76 \mathrm{~g} / \mathrm{cm}^{3}$ \\
\hline
\end{tabular}

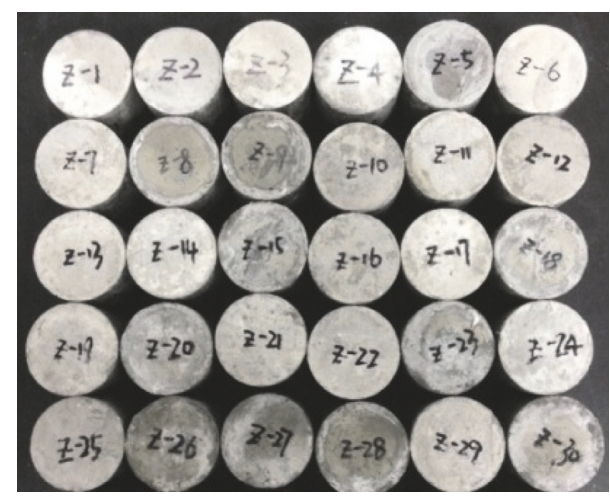

FIgURE 1: Experimental specimens with different carbon fiber contents.

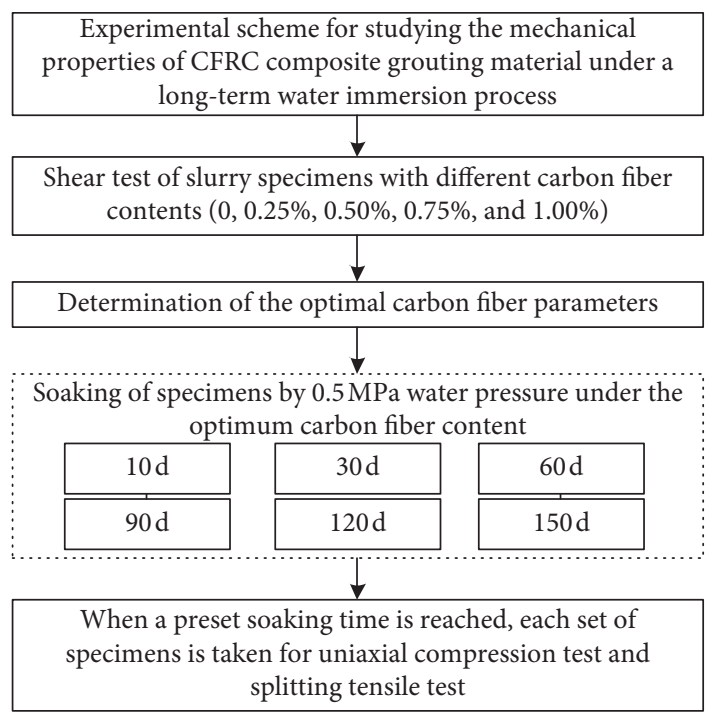

Figure 2: Experimental program.

them, a set of specimens were taken for compression and tensile tests at different durations ( 0 day or initial state, 10 days, 30 days, 60 days, 90 days, 120 days, and 150 days). The immersion test was conducted by using the YRK-1 rock dissolution apparatus, which was invented and developed by our research team [22]. This device is used to simulate the water-rock interaction (Figure 5). The pressure chamber has a pressure range of $0 \sim 1.2 \mathrm{MPa}$.

\section{Results and Discussion}

3.1. Shear and Stabilization Characteristics of Different Carbon Fiber Contents. The shear stress-displacement characteristics of the specimens are shown in Figure 6.

As seen in Figure 6,

(1) With different carbon fiber contents, the shear stressdisplacement characteristics of the specimens exhibited both peak and residual strength. Peak and residual strengths were observed at small and large strain levels, respectively.

(2) The shear strength was increasing when the carbon fiber content increased. Relative to the 0 carbon fiber content, the shear strength increased by $5.66 \% \sim 20.16 \%$, $12.86 \% \sim 30.23 \%, 18.26 \% \sim 38.76 \%$, and $22.64 \% \sim 43.41 \%$, while the carbon fiber content increased from $0.25 \%$ to $1.00 \%$ at different normal stress levels. In comparison, the higher the normal stress is, the greater the increase rate in the shear strength.

The shear strength parameters (internal angle of friction $\varphi$ and cohesion C) were determined based on the MohrCoulomb failure criterion. The computed values are shown in Figure 7.

The relationship between the unit carbon fiber content and the increment in the shear strength was defined by using the following equation:

$$
\Delta \lambda_{n}=\left(\frac{\lambda_{n}-\lambda_{0}}{\lambda_{0}}-\frac{\lambda_{n-1}-\lambda_{0}}{\lambda_{0}}\right) \times 100 \%
$$

where $\lambda$ represents the internal angle of friction, $\varphi$, or the cohesion, $C ; \Delta \lambda$ designates the unit carbon fiber content (in this paper, the unit carbon fiber content was $0.25 \%$ )for the increase in the internal angle of friction, $\varphi$, or the cohesion, $\mathrm{C} ; \lambda_{0}$ stands for the value of $\varphi$ or $\mathrm{C}$ when the carbon fiber content is 0 , and $n=1,2,3,4$ representing $0.25 \%, 0.50 \%, 0.75 \%$, and $1.00 \%$ of carbon fiber contents, respectively).

The unit increment in the shear strength parameters of the specimen (Figure 8) was calculated by using equation (1).

As shown in Figures 7 and 8,

(1) The specimen with no carbon fiber content had $32.94^{\circ}$ and $1.07 \mathrm{MPa}$ internal angle of friction and cohesion, respectively. The internal angle of friction 


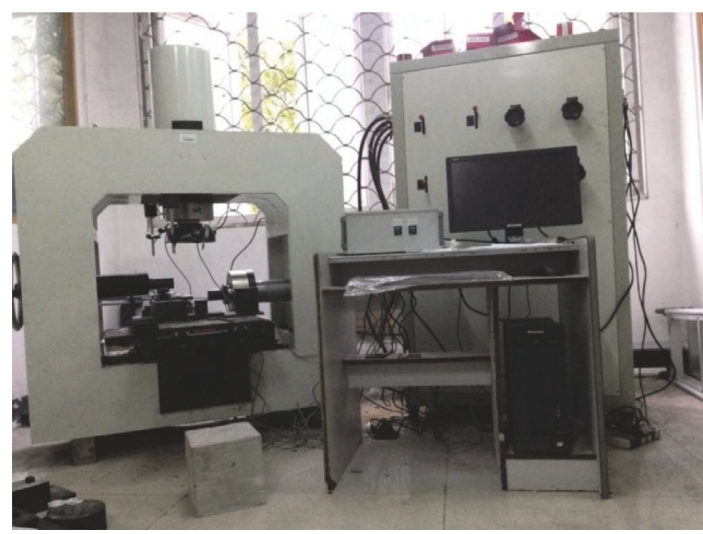

(a)

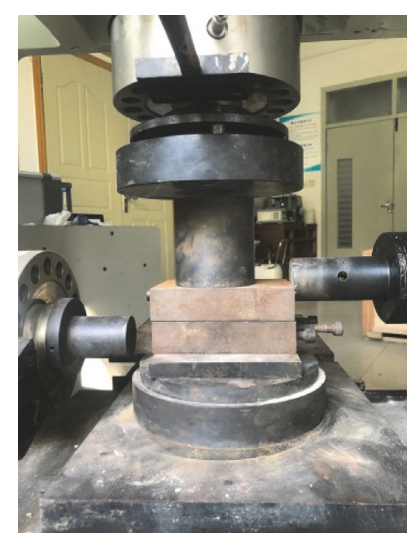

(b)

FIGURE 3: Shear test device: (a) YZW1000 computerized direct shear testing device; (b) shear loading device.

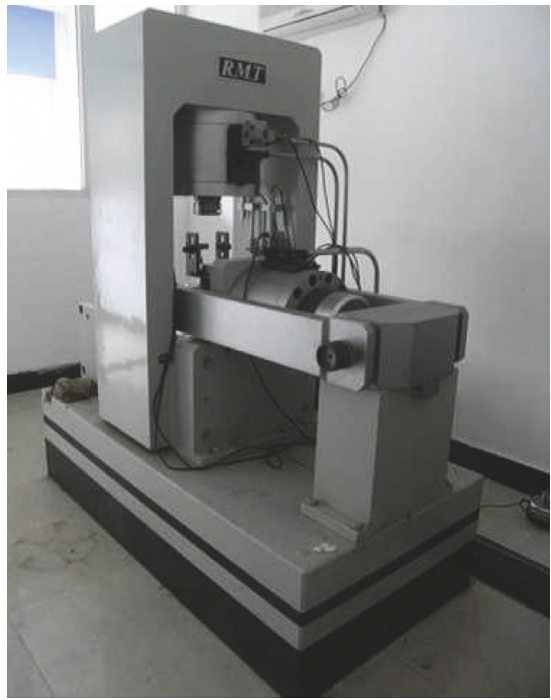

(a)

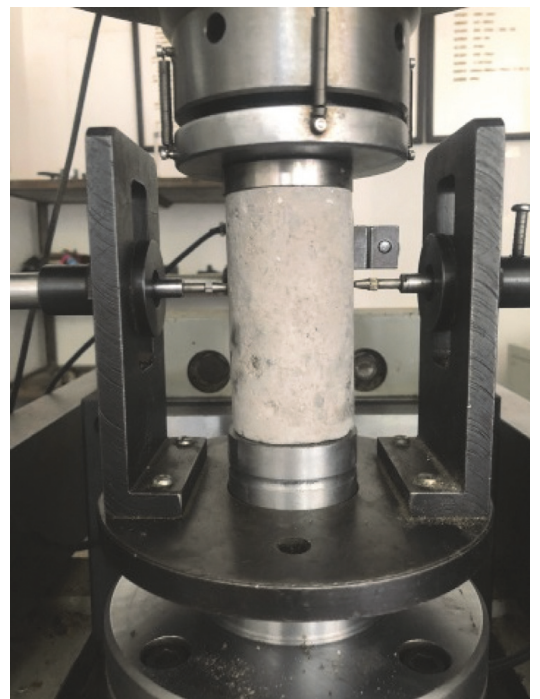

(b)

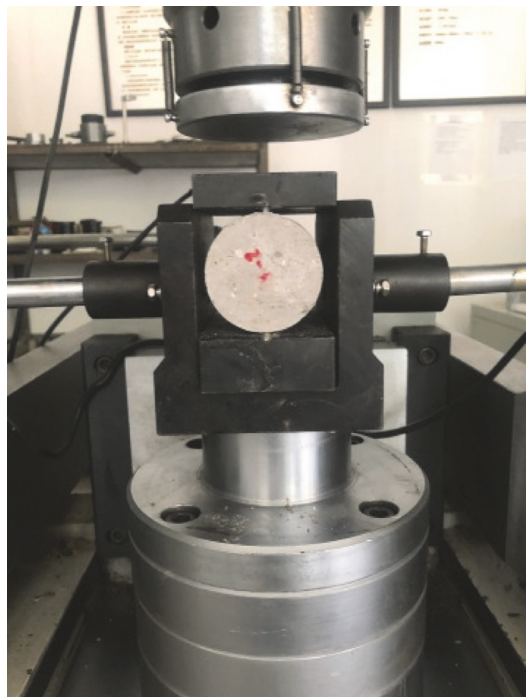

(c)

Figure 4: Uniaxial compression test and the splitting tensile testing devices: (a) RMT-150C rock mechanics test system; (b) uniaxial compression loading device; (c) splitting tensile loading device.

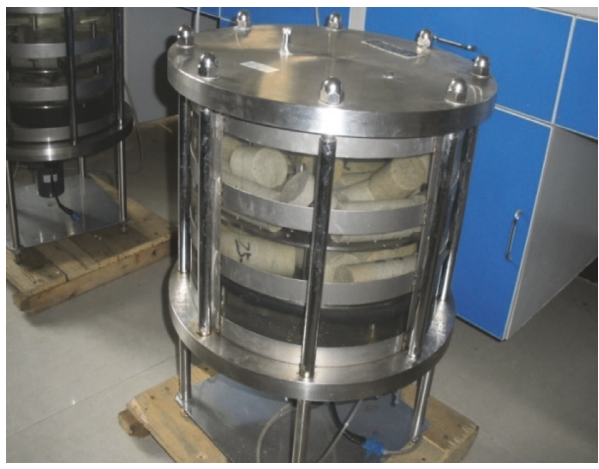

FIGURE 5: YRK-1 rock dissolution testing device.

was increasing by $1.46 \%, 3.16 \%, 4.95 \%$, and $5.77 \%$ when the carbon fiber content was gradually increased from $0.25 \%$ to $1.00 \%$. Similarly, the cohesion has been increased by $12.15 \%, 28.04 \%, 47.66 \%$, and $56.07 \%$. In comparison, the stabilization effect of carbon fiber on the cohesion, $\mathrm{C}$, of the specimen was particularly significant.

(2) The internal angle of friction per unit carbon fiber content and the cohesion have been increasing by $1.46 \%, 1.70 \%, 1.79 \%$, and $0.82 \%$, and $12.15 \%$, $15.89 \%, 19.62 \%$, and $8.41 \%$, respectively, while the carbon fiber content has been increased by $0.25 \%$, $0.50 \%, 0.75 \%$, and $1.00 \%$. In contrast, the increase in the shear strength parameters reached a peak value when the carbon fiber content increased from $0.5 \%$ to $0.75 \%$. However, the rate of increment was decreasing while the carbon fiber content exceeded the optimum range.

Failure modes of the specimens with different carbon fiber content are shown in Figure 9. 


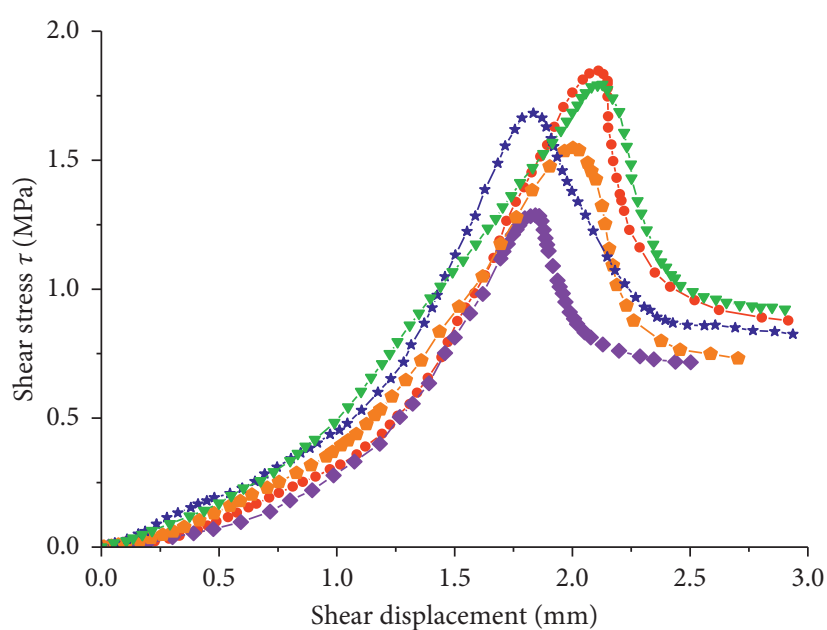

- - With $1.00 \%$ carbon fiber - - With $0.25 \%$ carbon fiber content

$-\nabla-$ With $0.75 \%$ carbon fiber $\multimap-$ With no carbon fiber content content

- - With $0.50 \%$ carbon fiber content

(a)

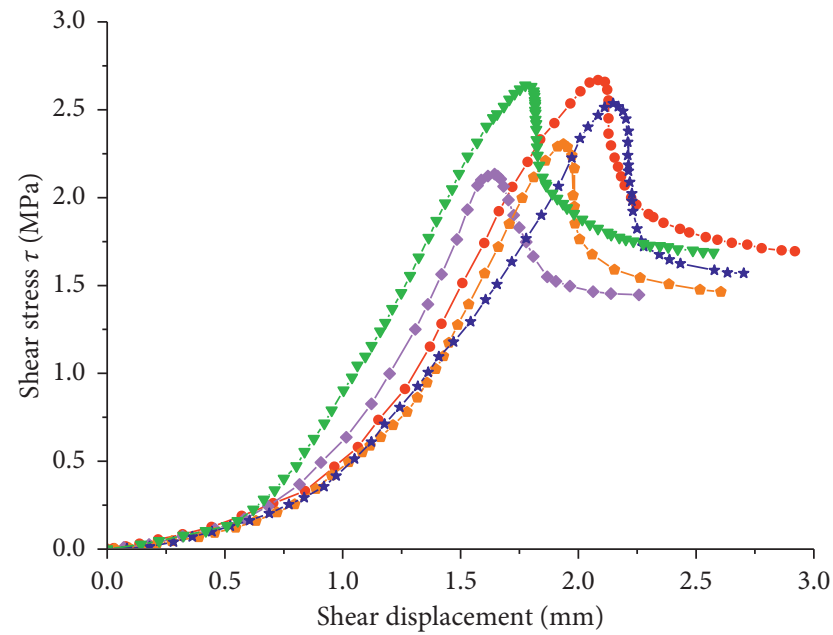

-- With $1.00 \%$ carbon fiber -- With $0.25 \%$ carbon fiber content content

$-\nabla-$ With $0.75 \%$ carbon fiber $\rightarrow-$ With no carbon fiber content content

- - With $0.50 \%$ carbon fiber content

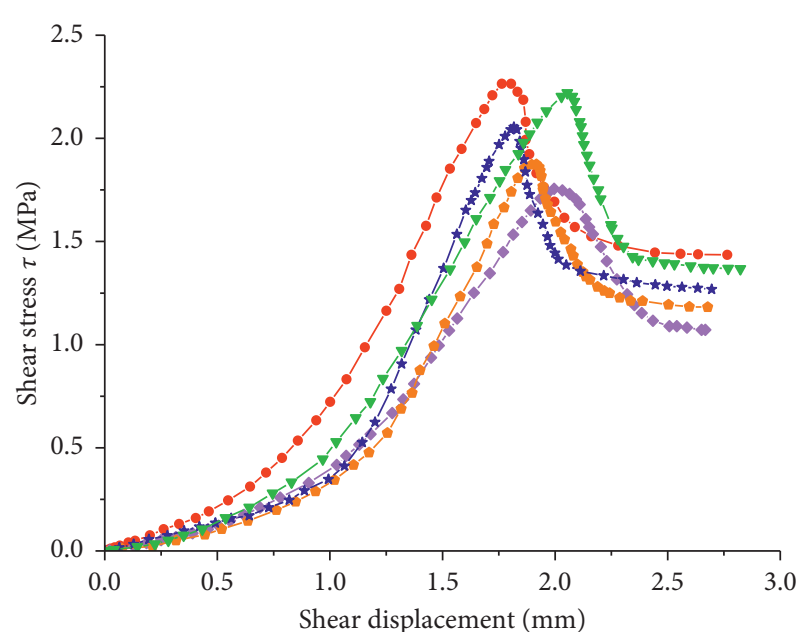

-- With $1.00 \%$ carbon fiber - - With $0.25 \%$ carbon fiber content content

$-\nabla-$ With $0.75 \%$ carbon fiber $-\bullet-$ With no carbon fiber content content

- - With $0.50 \%$ carbon fiber content

(b)

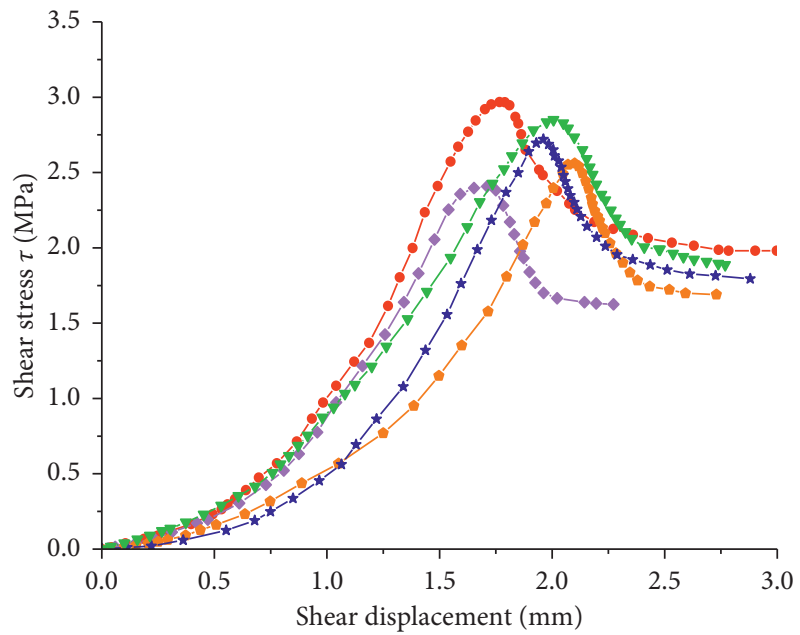

- - With $1.00 \%$ carbon fiber - - With $0.25 \%$ carbon fiber content content

$\rightarrow-$ With $0.75 \%$ carbon fiber $\longrightarrow$ - With no carbon fiber content content

— - With $0.50 \%$ carbon fiber content

(d)

Figure 6: Continued. 


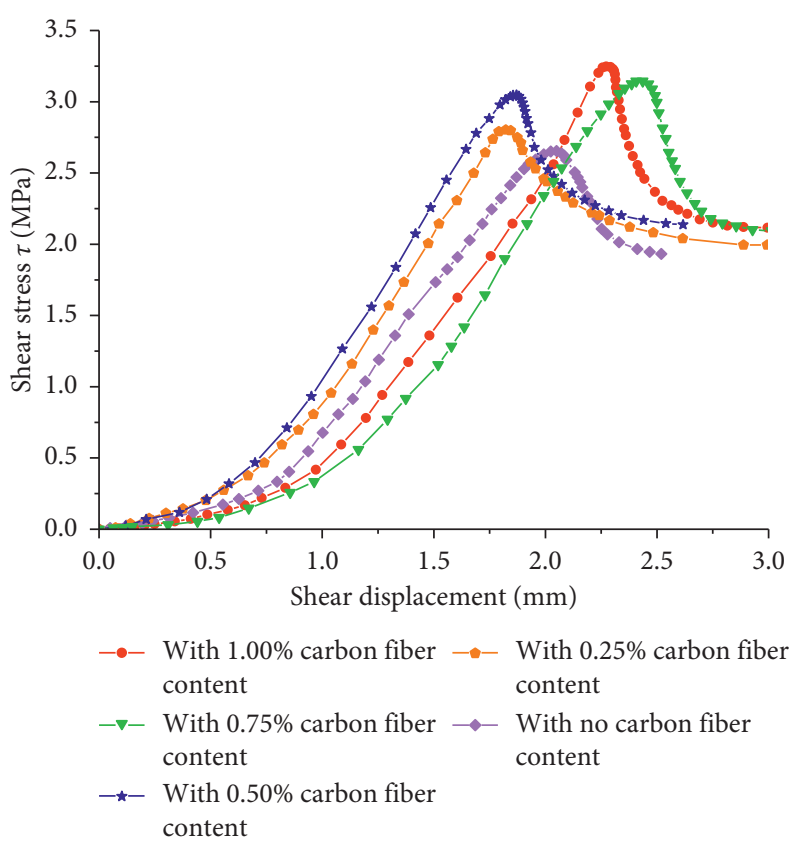

(e)

Figure 6: Shear stress-displacement characteristics at different normal stress levels: (a) $0.5 \mathrm{MPa}$; (b) $1.0 \mathrm{MPa}$; (c) $1.5 \mathrm{MPa}$; (d) $2.0 \mathrm{MPa}$; (e) $2.5 \mathrm{MPa}$.

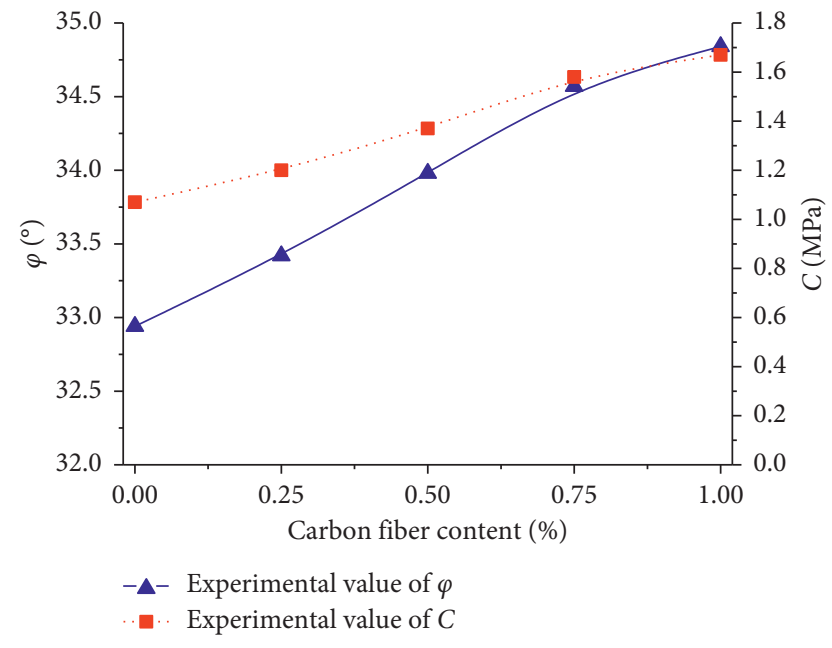

Figure 7: Computed shear strength parameters of the specimens with different carbon fiber contents.

The application of carbon fiber has a significant effect on the shear failure characteristics of the specimens (Figure 9) as follows:

(1) The top and bottom shear faces of the specimen (with no carbon fiber) were split by the occurrence of shear failure. Besides, the edges were peeled off, and the occurrence and expansion of the secondary crack was very noticeable.

(2) The shear displacement was increasing when the carbon fiber content increased from $0.25 \%$ to $1.00 \%$. Considerable displacement was observed between

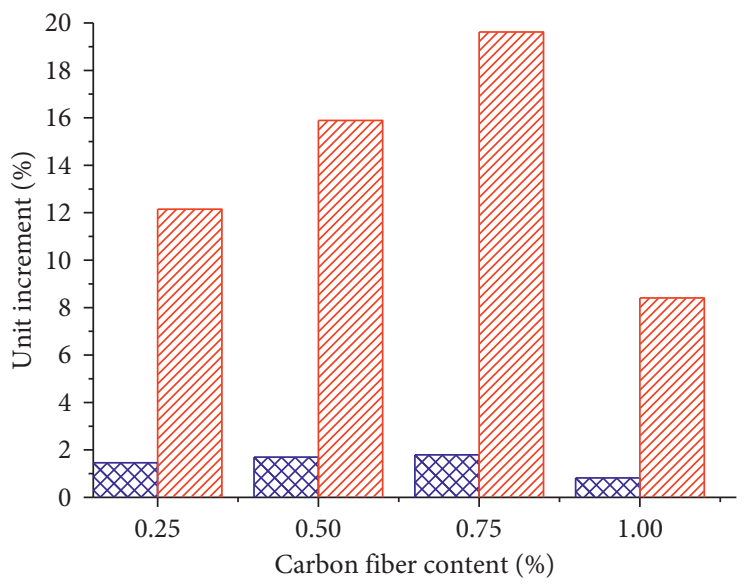

$\varphi$

VIIIA C

FIGURE 8: Incremental shear strength parameters of the specimen with different carbon fiber content.

the upper and lower shear planes. However, the contact areas were not sheared. Both the top and the bottom surface areas were not affected by the shearing process. Broken carbon fibers were observed on the shear surfaces.

Figure 10 is a schematic diagram that shows the distribution of the carbon fibers in the CFRC composite specimen. Carbon fiber plays two roles in the composite materials: one is to enhance the cementation strength and integrity of the composite components; the second is to limit 

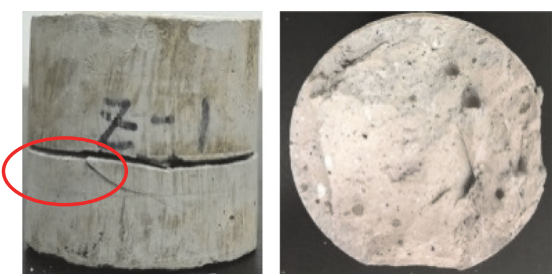

(a)
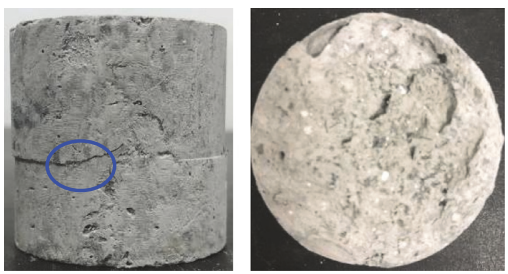

(c)
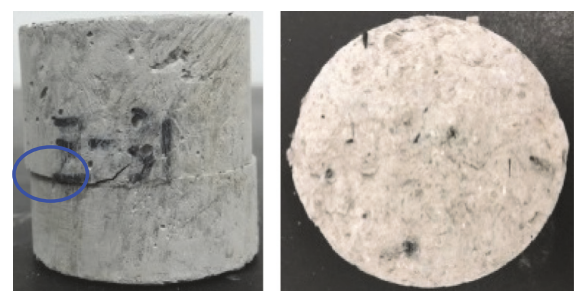

(e)
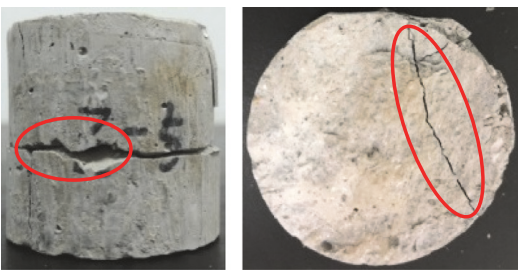

(b)
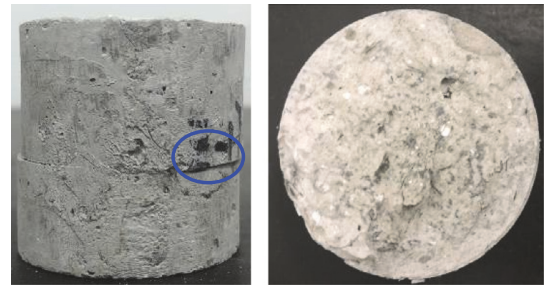

(d)
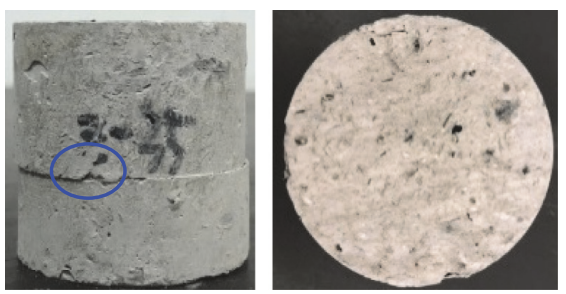

(f)

FIGURE 9: Failure modes of the specimens with different carbon fiber contents: (a) without carbon fiber; (b) without carbon fiber; (c) $0.25 \%$; (d) $0.50 \%$; (e) $0.75 \%$; (f) $1.00 \%$.

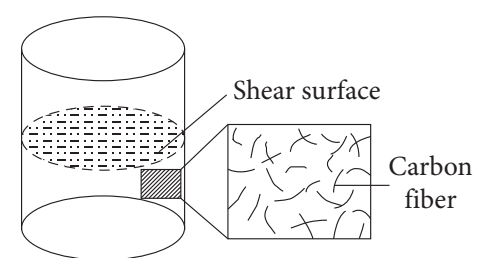

FIGURE 10: Schematic representation of carbon fiber distribution in the composite specimen.

the occurrence and expansion of microcracks during the shearing process to a certain extent (i.e., carbon fiber has high axial strength and modulus). The relative movement between the upper and lower shear planes of the specimen can be inhibited by using carbon fibers. Moreover, it has a good anchoring effect on the sheared specimen (improving the bonding between the top and bottom shear planes). Some carbon fibers were observed on the shear surfaces indicating the stabilization effect of carbon fiber on the shear resistance. As a result, crack propagation was minimized.

Based on the above analysis, the shear resistance of CFRC composites was gradually increased by the coupled action of carbon fiber (i.e., "reinforcement" and "anchor"). The optimum carbon fiber content was found to be $0.75 \%$.

3.2. Durability of CFRC Composite Specimens at Optimum Carbon Fiber Content. Figure 11 shows the degradation in

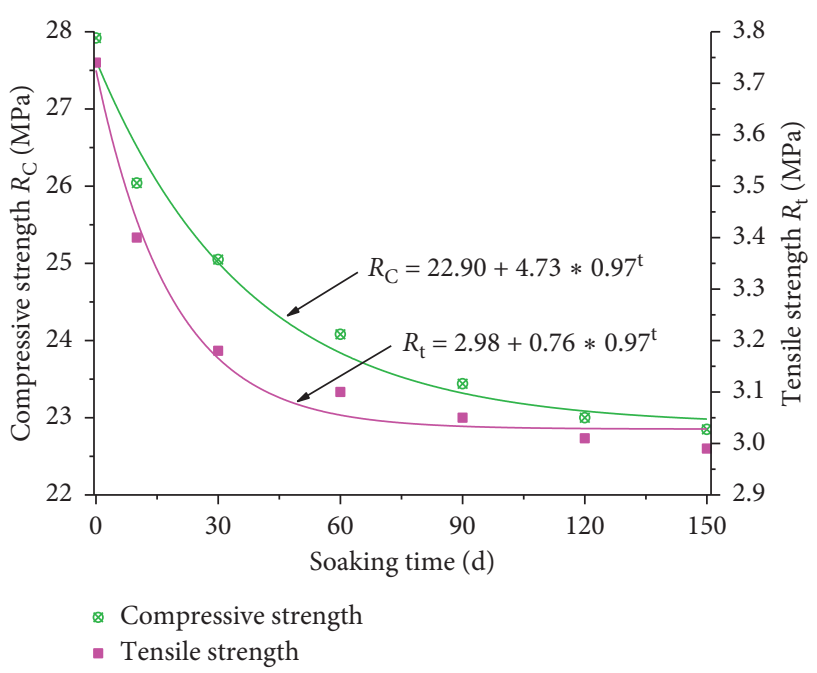

FIGURE 11: Degradation in the compressive and tensile strength of the specimens under long-term immersion.

the compressive and tensile strength of the composite specimens under different soaking duration.

It can be seen from Figure 11 that

(1) The initial compressive strength of the specimen was 27.92 MPa. However, the compressive strength decreased by $6.73 \%, 10.28 \%, 16.05 \%$, and $18.16 \%$ after $10,30,90$, and 150 immersion days, respectively. 
About $88.38 \%$ of the total degradation in the compressive strength occurred in 90 immersion days.

(2) The initial tensile strength of the specimen was 3.74 MPa. The tensile strength was reduced by $9.09 \%$, $14.97 \%, 18.45 \%$, and $20.05 \%$ after $10,30,90$, and 150 immersion days, respectively. Most importantly, about $92.02 \%$ of the total degradation in the tensile strength was observed in 90 immersion days.

(3) Under the long-term immersion, the compressive and tensile strength of the specimen showed a consistent degradation trend (i.e., a steep gradient was gradually followed by a gentle slope), and it can be expressed by the exponential function. A significant deterioration occurred in 90 immersion days, and it was becoming stable while the immersion time increased.

(4) The durability test results of this paper are in a good agreement with the previous studies. For example, the average bond strength of fiber concrete (fiber diameter $8 \mathrm{~mm}$ ) was degraded by $35.14 \%$ in 150 soaking days [23]. According to Zhang [13], the bond performance of CFRP-concrete was decreasing while the seawater immersion time increased, and the average bond strength was degraded by about $13 \%$ in 90 immersion days. In this paper, the mechanical properties of CFRC composites showed a relatively high degradation trend under the same soaking duration. Besides, the immersion process had a considerable hydrolysis effect on the specimens. Studies by Jiang et al. [24] and Wen [25] revealed that the presence of water pressure increased the permeability of the samples, and the infiltrated water yielded low adhesion of fibers and gelation in the specimens [26]. Hence, the effect of degradation was very noticeable. For example, Ma et al. [26] and other studies showed that when the hydrostatic pressure value increased from $0.3 \mathrm{MPa}$ to $0.7 \mathrm{MPa}$, the diffusion depth of the chloride ion increased by more than $100 \%$. Meanwhile, compared with the CFRC composite grouting material, the ordinary cement shows considerable deterioration in strength under the long-term water immersion process. For example, the average compressive strength and elastic modulus of cement asphalt mortar were reduced by $46.5 \%$ and $47.5 \%$ (within 30 days immersion time), respectively [27]. Similarly, the compressive strength of cement mortar was decreased by $36.39 \%$ after $48 \mathrm{~h}$ immersion time [28]. Moreover, the compressive strength of cement mortar was decreased by 35 to $39 \%$ within 50 days immersion time [29]. Based on pertinent literature, the mechanical strength of ordinary cement has been significantly decreasing under a long-term water immersion process. Therefore, one should consider the degradation effect of water immersion on the CFRC composite grouting material.

The failure characteristics of the specimens under a longterm immersion process were investigated by using the failure modes of uniaxial compression and splitting tensile tests (Figures 12 and 13).

Figure 12 shows that the uniaxial compression failure characteristics of the composite specimens under different immersion durations were significantly different. In the initial phase (without immersion), the carbon fiber improved the brittleness of the specimens to some extent, but there was no sign of deformation before the failure. The local tensile failure characteristics of the specimen were very noticeable. The carbon fibers were broken and pulled out of the specimens. After 30 immersion days, the failure modes of the specimens showed a dramatic change, and the tensile and shear cracks exhibited a reduction and increment trend, respectively. The number of cracks was small after 90 150 immersion days. Although there were continuous main cracks and development of local secondary cracks on the body of the specimens, obvious falling off phenomenon was not observed, indicating the softening performance of the composite specimens and the overall properties (the brittle failure was exhausted).

The tensile failure characteristics of the composite specimens under different immersion time were quite different (Figure 13): the failure surfaces were regular, and the integrity of the specimen was good within 30 immersion days. The fracture surfaces of the specimens were shifted from the loading line, and a large amount of carbon fiber was observed on the surface within 90 150 immersion days. Therefore, the degradation of the specimen was critical, and the resulting failure surface was complex under the longterm water immersion process.

3.3. Degradation Mechanism ofCFRC Composites. According to the above analysis, the carbon fiber plays the roles of "reinforcing" and "anchoring" on the CFRC composite. Under the long-term immersion of water, the rate of degradation in the compressive and tensile strength of the specimen was initially steep and then gradually reduced. The failure modes changed significantly. There are two main reasons for deterioration.

On the one hand, the long-term immersion yields deterioration in the physical and mechanical properties of the composite specimen. Cement-based materials showed a significant deterioration trend under the long-term immersion [30]. Firstly, the main product of hydrated cement is hydrated calcium silicate (C-S-H) gel. The load is going to be carried by the silicon chain and calcium-oxygen bond in the C-S-H structure when it has no water molecule. A calcium-oxygen bond was developing between the broken silicon chains while the silicon chain damaged. Some of the calcium atoms act to bridge the silicon chain. However, under the immersion condition of CFRC composites, water molecules diffuse into the interior of the composite by capillary absorption. A large number of water molecules infiltrate between the calcium-oxygen bonds in the C-S-H structure, and thereby reduce the interaction between the calcium and oxygen atoms in the silicon chains. As a result, the strength of the gel will reduce, and this will further 


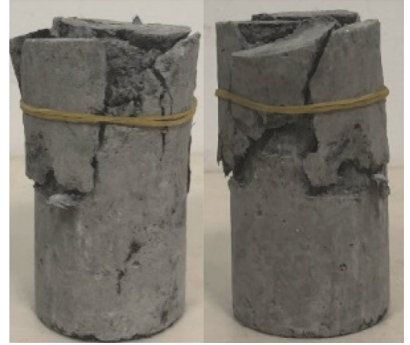

(a)

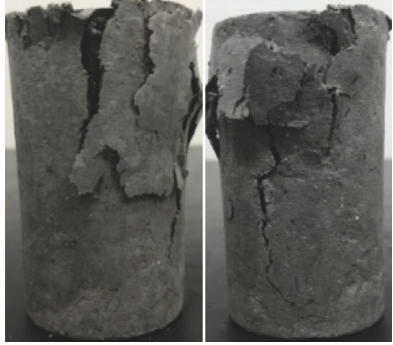

(b)

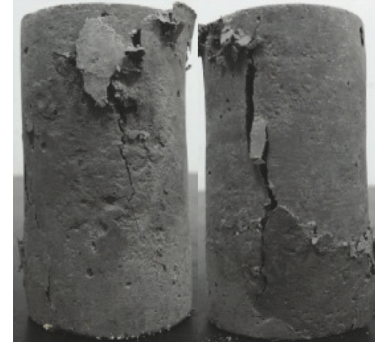

(c)

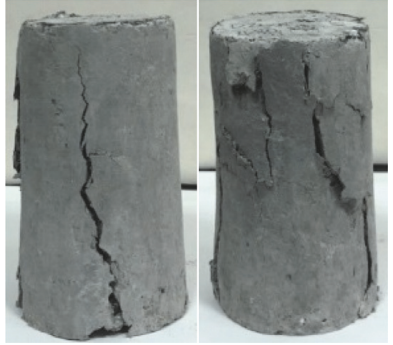

(d)

Figure 12: Failure modes under uniaxial compression tests: (a) initial state; (b) 30 day; (c) 90 day; (d) 150 day.

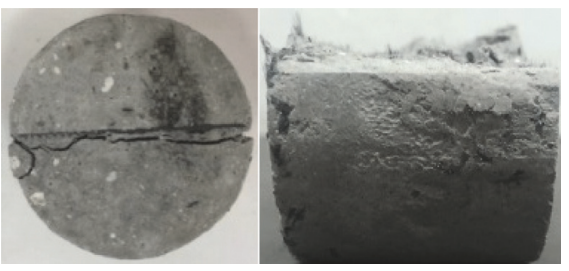

(a)

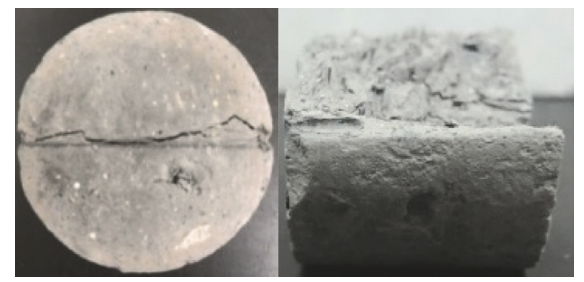

(c)

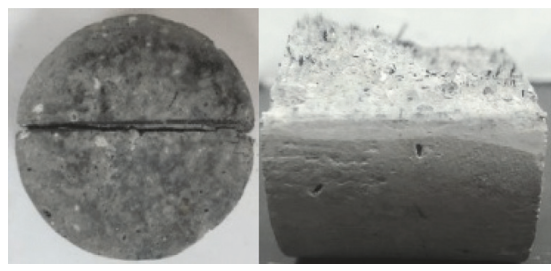

(b)

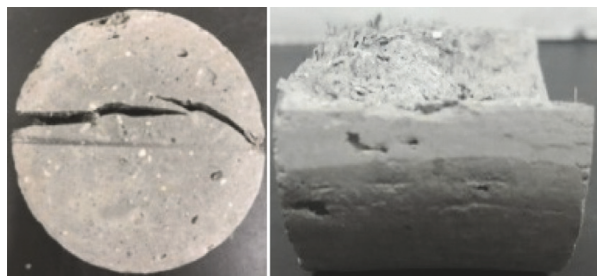

(d)

FIGURE 13: Failure modes under splitting tensile tests: (a) initial state; (b) 30 day; (c) 90 day; (d) 150 day.

facilitate the degradation in the mechanical properties of the composite specimen. The overall properties of the specimen become soft as a weakening result of water molecules and provoke transition between brittle and ductile states under uniaxial compression. Secondly, carbon fiber has poor hydrophilicity, and it will gradually reach aging condition under the long-term immersion conditions [31]. Besides, the specific characteristics of the specimen will also degrade. The mechanical anchoring force and chemical adhesion of the carbon fiber were decreasing when the water molecules seeped into the composite specimen and led to a decrease in the boding performance [23]. Under the external force, the carbon fiber will show the phenomenon of falling off as a "reinforced" material as shown in Figure 14 (image magnification is 500 times).

On the other hand, water pressure has a triggering effect on the deterioration of the composite specimen. Specimens will inevitably have initial defects such as pores and fissures that will further propagate under the action of water pressure. According to Wang et al. [32], the extent of damage was increased by 2.85 and 6.63 fold when the water pressure was 0.3 and $0.7 \mathrm{MPa}$, respectively. A similar finding was also found by Jiang et al. [24] and Wen [25]. The presence of water pressure promotes the expansion and development of new cracks (an active zone for water

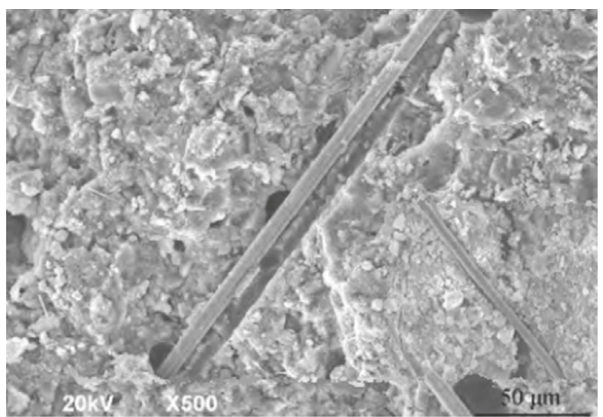

FIGURE 14: Carbon fiber "reinforced" shedding phenomenon under long-term immersion.

molecules) and facilitates the occurrence of local failure. The failure mode was propagated from the loading plane to the irregular surface. As a result of weak planes (due to the development of local failures), the transition in the failure mode was occurred.

Based on a comprehensive analysis, the long-term water immersion process has a considerable effect on the microscopic and macroscopic mechanical properties, and the failure characteristics of the specimens. During the immersion process, the presence of water molecules in the body of the specimens has a negative impact on the interaction 
between the calcium and oxygen atoms. In the meantime, the presence of water is responsible for the expansion of microcracks, and development of new cracks and local failures.

\section{Conclusions and Recommendations}

(1) The shear strength under different normal stresses, the internal angle of friction, and the cohesion were increasing by $(5.66 \% \sim 20.16 \%, 12.86 \% \sim 30.23 \%$, $18.26 \% \sim 38.76 \%$, and $22.64 \% \sim 43.41 \%), \quad(1.46 \% \sim$ $5.77 \%)$, and $(12.15 \% \sim 56.07 \%)$, respectively, while the carbon fiber content increased from $0.25 \%$ to $1.00 \%$. The optimum carbon fiber content was found to be $0.75 \%$ (i.e., the internal angle of friction and cohesion were increased by $1.79 \%$ and $19.62 \%$ per unit carbon content, respectively).

(2) The use of carbon fiber, on the one hand, is similar to the "reinforced" material, and it can enhance the cementation strength and integrity of the composite specimen; on the other hand, it can limit the occurrence and expansion of microcracks during the shearing process so that the comprehensive shear resistance of the CRFC composite grouting material was significantly improved.

(3) The compressive and tensile strength of the specimen showed a consistent deterioration trend (i.e., a steep gradient was gradually followed by a gentle slope) under the long-term water immersion process. The rate of deterioration was remarkable within $90 \mathrm{im}$ mersion days. About $90 \%$ of the total degradation in the compressive and tensile strength has occurred in 90 immersion days (i.e., $16.05 \%$ and $18.45 \%$, respectively). In comparison, the degradation in the tensile strength $(20.05 \%)$ was slightly higher than the compressive strength (18.16\%).

(4) Under the long-term water immersion process, the properties of the specimens were gradually deteriorating, the carbon fibers were gradually reaching a fatigue stage, and the bonding properties of carbon fiber was decreasing, which resulted in a reduction in the compressive and tensile strength. The uniaxial compression failure mode changed from brittle to ductile, and the development of local failure was very noticeable.

(5) Based on the findings of this paper, groundwater has a significant impact on the mechanical properties of grouted rock mass such as dam foundations and abutments. Therefore, the degradation in the grouting materials has to be considered in practical cases.

\section{Data Availability}

The data used to support the findings of this study are available from the corresponding author upon request.

\section{Conflicts of Interest}

The authors declare no conflicts of interest.

\section{Authors' Contributions}

Jianlin Li organized the research. Yao Xiao performed the shear tests and the immersion test. Yao Xiao and Huafeng Deng wrote the manuscript. Huafeng Deng and Eleyas Assefa checked the manuscript.

\section{Acknowledgments}

The authors gratefully acknowledge the financial support from the National Nature Science Foundation of China (Nos. 51679127 and 51439003) and Key Laboratory of Geological Hazards on Three Gorges Reservoir Area (China Three Gorges University), Ministry of Education Open Fund Project (No. 2018KDZ04).

\section{References}

[1] M. Smith, "New developments in carbon fiber," Reinforced Plastics, vol. 62, no. 5, pp. 266-269, 2018.

[2] K. Acatay, "6-Carbon fibers," Fiber Technology For FiberReinforced Composites, pp. 123-151, Woodhead Publishing, Cambridge, UK, 2017.

[3] T. Fumkawa Shigcru and Yukikazu, "Production and mechanical properties of carbon fiber reinforced cement composite," in Proceedings of the Japan Congress on Materials Research, pp. 149-152, Kyoto, Japan, 1987.

[4] P.-W. Chen and D. D. I. Chung, "Concrete reinforced with up to 0.2 vol\% of short carbon fibers," Composites, vol. 2, no. 1 , pp. 33-35, 1993.

[5] X. Liu, T. Wu, X. Yang, and H. Wei, "Mechanical properties and microstructure of fiber reinforced high-strength lightweight aggregate concrete," Journal of Building Materials, vol. 22, 2019, http://kns.cnki.net/kcms/detail/31.1764.TU.20181229.1431. 028.html.

[6] Y. Zhang, Q. Y. Yin, and S. R. Xin, "Study on mechanical properties of carbon fiber cement-based materials," Henan Building Materials, vol. 5, pp. 62-66, 2011.

[7] B. Xiong, Z. Wang, C. Wang, Y. Xiong, and C. Cai, "Effects of short carbon fiber content on microstructure and mechanical property of short carbon fiber reinforced $\mathrm{Nb} / \mathrm{Nb}_{5} \mathrm{Si}_{3}$ composites," Intermetallics, vol. 106, pp. 59-64, 2019.

[8] R. Hai, Y. G. Zhang, F. Yue, and K. R. Wu, "Effect of fiber content on physical and mechanical properties of carbon fiber reinforced cement-based material," Journal of Building Materials, vol. 13, no. 3, pp. 300-303, 2010.

[9] H. Yu, M. Y. Zhou, and Q. Q. Gu, "The test analysis on the mechanical property of carbon fiber reinforced concrete," Journal of Changzhou Institute of Technology, vol. 19, no. 5, pp. 26-30, 2006.

[10] J. Sun and S. H. Wei, "Study on the preparation and properties of carbon fiber reinforced cement matrix composites," New Building Materials, vol. 10, pp. 61-64, 2018.

[11] C. Wang and X. S. Zhang, "Study of carbon-fiber-reinforced cement-based composites," China Building Materials Science \&Technology, vol. 5, pp. 5-9, 2007.

[12] J. Shrestha, D. W. Zhang, and T. Ueda, "Durability performances of carbon fiber-reinforced polymer and concrete- 
bonded systems under moisture conditions," Journal of Composites for Construction, vol. 20, no. 5, pp. 1-12, 2016.

[13] J. Zhang, Durability Study on CFRP and the Interfacial Performance between CFRP and Concrete in Sea Environment, MS thesis, Dalian University of Technology, Dalian China, 2013.

[14] Y. Z. Gong, J. W. Zhang, L. Z. Jiang, and Y. M. Tu, "Experimental research on the compression performance and the influence of artificial seawater corrosion on the CFRP tendons," Industrial Construction, vol. 40, no. 3, pp. 94-97, 2010.

[15] H. T. Ren, A. N. Hu, and G. F. Zhao, "The influence of the freeze-thaw action on behavior concrete beams strengthened by glass fiber reinforced plastics," China Civil Engineering Journal, vol. 37, no. 4, pp. 104-110, 2004.

[16] S. S. Li, "Property optimization test of new cement-based grouting material," Coal Technology, vol. 36, no. 8, pp. 169-170, 2017.

[17] L. Tiejiong, M. R. Sergio, and V. Adelino, “Time-dependent behavior of concrete beams prestressed with bonded AFRP tendons," Composites Part B, vol. 97, pp. 1-8, 2016.

[18] K. Minho, S. Hyunsu, and K. Jinsup, "Seismic performance of RC-frame structures with GFRP infill panels," Composite Structures, vol. 160, pp. 722-733, 2017.

[19] M. Davood, A. H. Seyed, and B. R. Eyed, "Influence of different bonding and wrapping techniques on performance of beams strengthened in shear using CFRP reinforcement," Construction and Building Materials, vol. 116, pp. 310-320, 2016.

[20] Y. H. Zhang, L. P. Yao, C. F. Nong, Z. Y. Liu, H. Cheng, and X. L. Zhang, "Mechanical properties of bamboo charcoal fiber reinforced cement-based composite," Journal of Civil Engineering and Management, vol. 34, no. 2, pp. 91-94, 2017.

[21] J. L. Shi, S. Tian, T. J. Zhao, and J. Shang, "Experimental study on the tensile properties of natural fiber reinforced cementbased materials," China Concrete and Cement Products, vol. 3, pp. 55-57, 2015.

[22] H. F. Deng, J. L. Li, K. W. Wang, J. Liu, M. Zhu, and T. Lu, "Research on secondary porosity changing law of sandstone under saturation-air dry cycles," Rock and Soil Mechanics, vol. 33, no. 2, pp. 483-488, 2012.

[23] B. Huang, C. H. Lu, N. H. He, and T. S. Chu, "Degradation of bond between GFRP bars and concrete in erosive environment," Technology and Market, vol. 25, no. 10, pp. 18-21, 2018.

[24] Y. C. Jiang, F. Y. Liu, and J. Gong, "A study on the Cl-penetrability performance of high performance concrete under cyclic compressive stress or high hydraulic pressure," China Building Materials Science \& Technology, vol. 3, pp. 29-33, 2013.

[25] X. W. Wen, The Permeability and the Performance of the Electric Conduction of the Carbon Fiber Reinforced Cement Composite under Water, Shandong University, Jinan, China, 2010.

[26] Z. M. Ma, T. J. Zhao, Y. D. Zhao, and F. Z. Zhu, "Experiment and study chloride in concrete on transmission characters of under hydrostatic pressure," Highway, vol. 12, pp. 168-171, 2012.

[27] H. Xu, H.-S. Lin, P. Wang, and H. Yan, "The influence of water immersion on the mechanical property of cement asphalt mortar and its implications on the slab track," Journal of Vibroengineering, vol. 19, no. 1, pp. 477-486, 2017.

[28] Q. F. Zhang, "Experiment research to compressive resistance of explosive liningafter long-term immersion," Coal Technology, vol. 37, no. 9, pp. 171-173, 2018.

[29] D. H Jing, S. Y. Cao, and H. Chen, "Axial compression performance investigation of brick masonryafter being long- term soaked in water and air-dried," Sichuan Building Science, vol. 43, no. 2, pp. 29-32, 2017.

[30] C. Zhang, Study on Effects of Water Content on Mortar's Mechanical Properties, Agricultural University Shandong, Taian, China, 2018.

[31] J. P. Meng, J. W. Liu, and J. N. Lin, "Study on the influence of PVA content on mechanical properties of cement-based composites under seawater corrosion," Henan Building Materials, vol. 4, pp. 464-466, 2018.

[32] X. B. Wang, C. L. Zhang, and Y. D. Zhao, "Study on the influence of hydrostatic pressure on the chloride penetration into concrete," Concrete, vol. 5, pp. 41-44, 2016. 


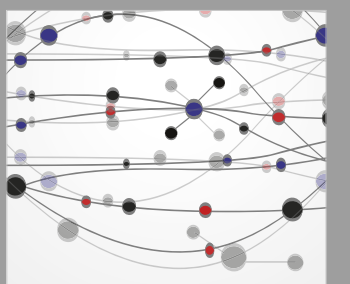

The Scientific World Journal
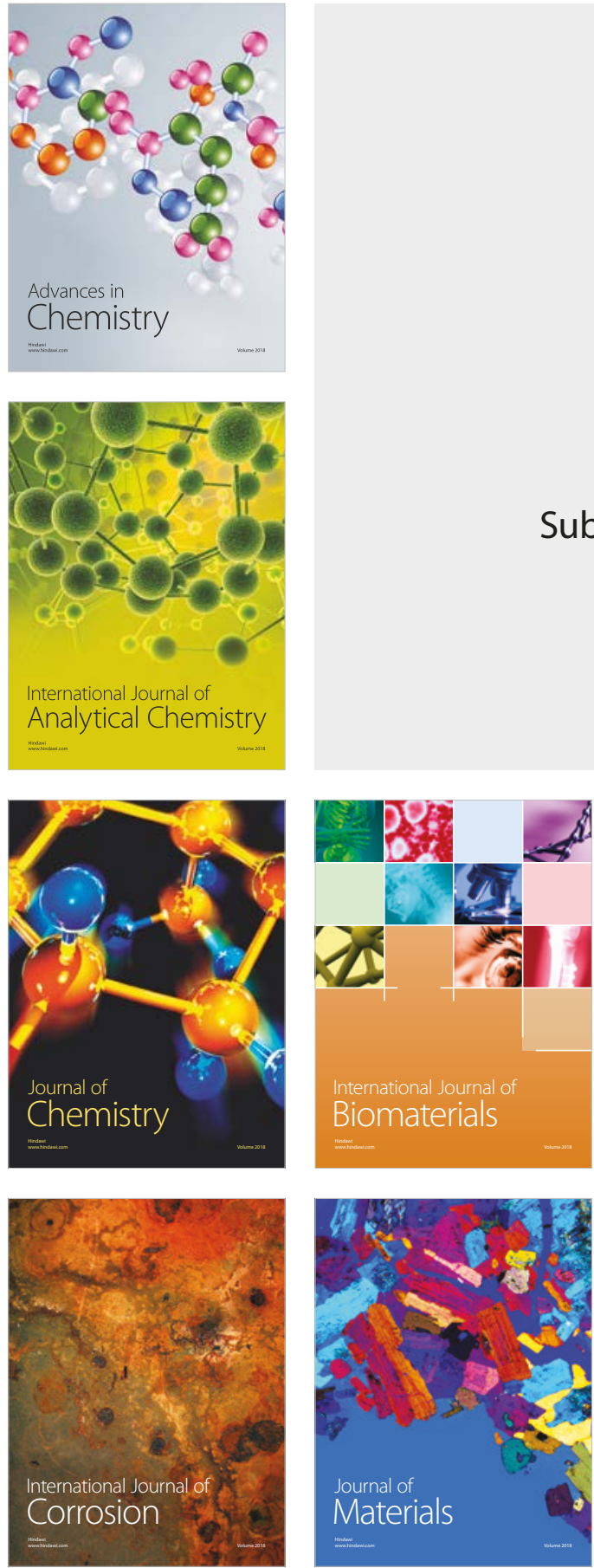

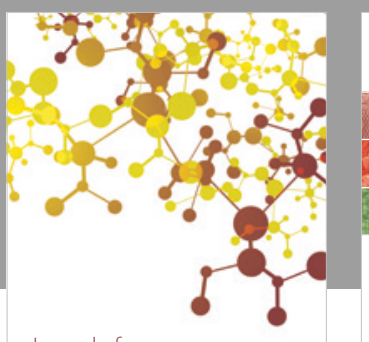

Journal of

Applied Chemistry
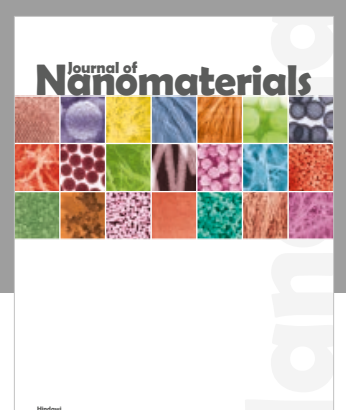

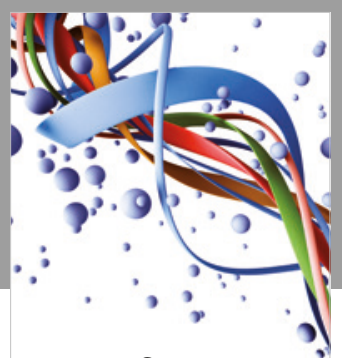

Scientifica

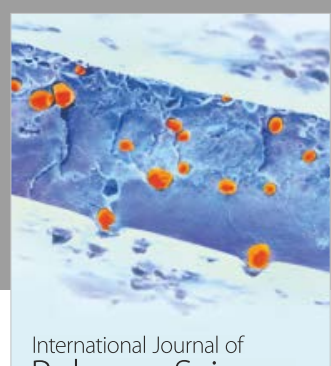

Polymer Science

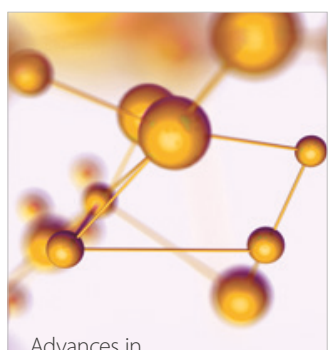

Physical Chemistry
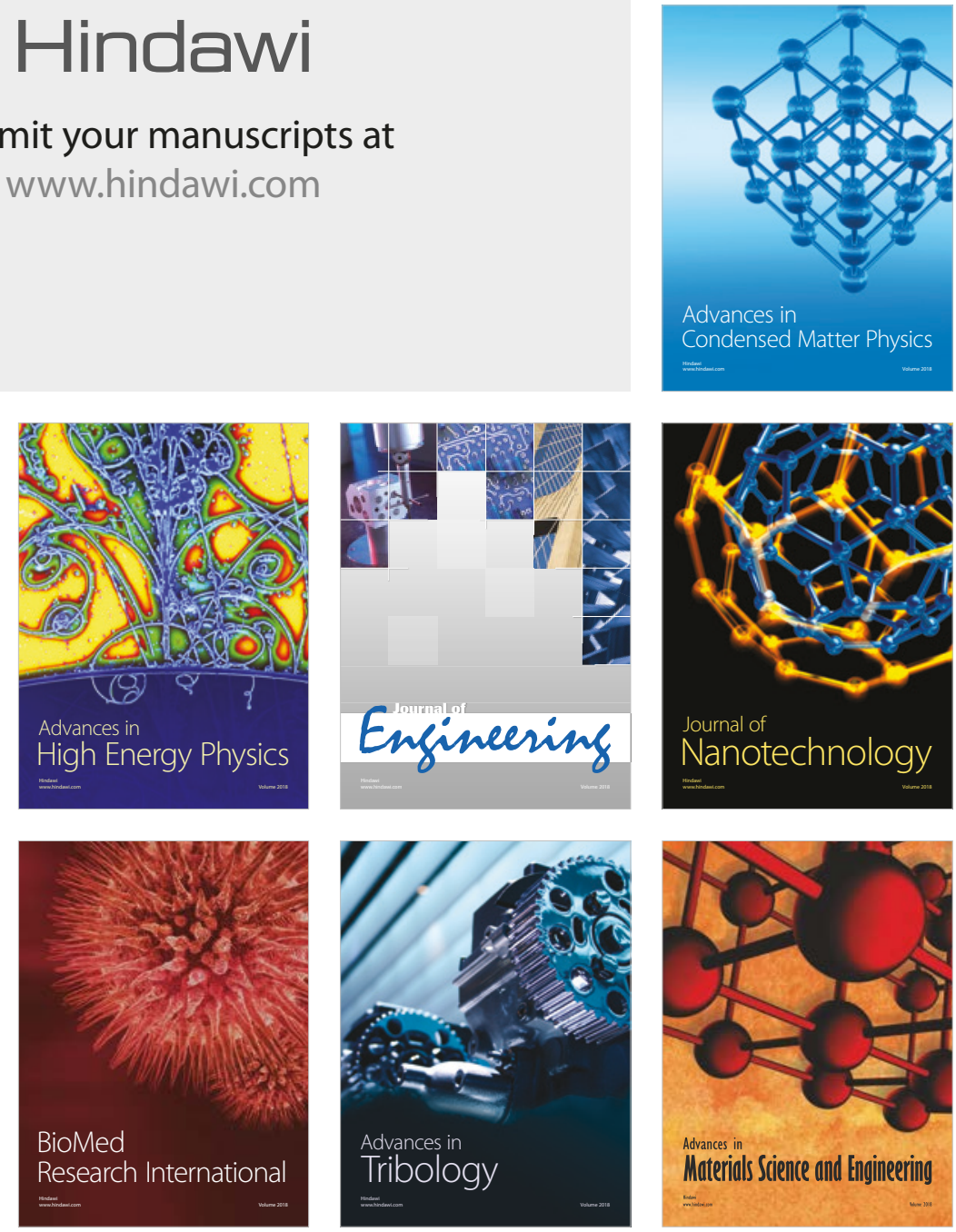